Int. J. Dev. Biol. 49: 585-593 (2005)

doi: $10.1387 / \mathrm{ijdb} .041930 \mathrm{fp}$

\title{
Flowering: a time for integration
}

\author{
FRANÇOIS PARCY* \\ Physiologie Cellulaire Végétale. CNRS UMR5168- CEA- INRA- UJF, Grenoble, France
}

\begin{abstract}
Flowering time is under the control of multiple environmental cues such as photoperiod and exposure to cold temperatures (vernalization). A few regulators named integrators of flowering time signals ( $L E A F Y$, SOC1 / AGL20 and FT) integrate inputs from the different flowering cascades and convey the resulting outcome to floral meristem identity genes at the shoot apex. Here we review the current knowledge about the expression of integrators, their mode of action, their potential target genes and the nature of their mutual interactions. We emphasize the questions that have been generated by recent progress in this field and that remain to be addressed.
\end{abstract}

KEY WORDS: flowering, floral pathway integrator, LEAFY, SOC1, FT

"Get yourselves organized down there" Wallace talking to the sheep in A close shave by Nick Park

\section{Introduction}

As for other plants, the floral transition is one the most drastic changes occurring during Arabidopsis thaliana life cycle. The shoot apical meristem switches from the production of leaves with associated secondary shoot meristems to bractless flowers (Hempel and Feldman, 1993, Suh et al., 2003). This transition is abrupt and irreversible, suggesting it is regulated by a robust gene regulatory network capable of driving sharp transitions. The moment at which this transition occurs is precisely determined by environmental and endogenous signals. Arabidopsis flowers earlier in long than in short days (it is a facultative long-day plant). Also, many Arabidopsis strains flower earlier after a period of cold exposure (a treatment named vernalization). Genetic analyses identified a whole set of flowering time mutants that were subsequently assigned to four major genetic pathways according to their response to vernalization or day length (Martinez-Zapater et al., 1994). The field of flowering time has been organized around these four pathways, with the photoperiod and vernalization pathways mediating the response to environmental cues and the autonomous and the gibberellin (GA) pathways acting largely independently from these external signals (Figure 1). A large number of genes acting within these pathways have been cloned and current analyses aim at understanding how they are linked to each other and how the corresponding proteins function (Amasino, 2004, Araki, 2001, Bastow and Dean, 2003, Boss et al., 2004, Jack, 2004, Mouradov et al., 2002, Simpson and Dean, 2002, Simpson etal., 1999, Sung and Amasino, 2004a). Two genes play a prominent role at the "bottom" of these promotion cascades. The CONSTANS (CO) gene is probably the most downstream actor, specific for the photoperiod pathway (Figure 1) and both the light and the internal clock precisely regulate the CO protein accumulation (Valverde et al., 2004). The FLOWERING LOCUSC (FLC) gene is the point of convergence of the autonomous and vernalization pathways (Figure 1). Ultimately and in part through $\mathrm{CO}$ and FLC, the flowering signals lead to the induction of a set of genes called floral meristem identity (FMI) genes and responsible for the fate change of the meristems emerging on the flanks of the shoot apex (Long and Barton, 2000). This group of genes includes $\angle E A F Y$ ( $L F Y), A P E T A L A 1$ (AP1) and CAULIFLOWER $(C A L)$, expressed in early floral stages and responsible for their floral fate (Kieffer and Davies, 2001, Lohmann and Weigel, 2002).

Recently, three genes were shown to make the junction between the different flowering-time cascades and the FMI genes (Figure 1). These genes were named Floral Pathway Integrators because they are able to integrate a balance of stimulations originating from the different pathways and convert these heterogeneous inputs into an induction of FMI genes, thereby initiating the production of the first floral meristems (Simpson and Dean, 2002).

Several recent excellent reviews deal with the control of flowering time (Amasino, 2004, Araki, 2001, Bastow and Dean, 2003, Boss et al., 2004, Jack, 2004, Mouradov et al., 2002, Simpson and Dean, 2002, Simpson et al., 1999, Sung and

Abbreviations used in this paper: AGL20, AGAMOUS-like 20; AP1, APETALA1; CAL, CAULIFLOWER; CO, CONSTANS; FLC, FLOWERING LOCUS C; FT, FLOWERING LOCUS T; GA, gibberellins; GFP, green fluorescent protein; LD, long days; LFY, LEAFY; SD, short days; SOC1, SUPPRESSOR OF CONSTANS OVEREXPRESSION; WUS, WUSCHEL.

\footnotetext{
*Address correspondence to: Dr. François Parcy. PCV/DRDC Bat. C2. 17, avenue des martyrs, 38054 Grenoble, cedex 9 , France. Fax +33-4-3878-5091. e-mail: francois.parcy@cea.fr
} 
Amasino, 2004a). In this paper, I deliberately chose to focus on Arabidopsis Floral Pathway Integrators (thereafter named integrators) and to review and question in some detail the available experimental evidence subtending current models of gene regulatory network leading to flowering.

\section{Identity of floral pathway integrators}

The three genes shown to integrate the influence from different pathways are $\angle E A F Y(L F Y)$, FLOWERING LOCUS T (FT) and SUPPRESSOROFCOOVEREXPRESSION(SOC1)/AGAMOUSlike 20 (AGL20) (thereafter named SOC1). I will first introduce these genes and their expression and then focus on their regulation by the pathways promoting flowering.

\section{LEAFY (LFY)}

The $\angle E A F Y$ gene plays a key role during flower development and can be considered both as a flowering time gene and a meristem identity gene.

$\angle E A F Y$ expression precedes the floral transition: it is first detected (both the RNA and the promoter activity) in young leaf primordia and it increases to reach a maximum in young floral meristems (Blazquez etal., 1998, Blazquez etal., 1997) (Figure 2). Plants with increased $\angle F Y$ gene copy number or $\angle F Y$ constitutive expression flower early (Blazquez etal., 1997, Weigel and Nilsson, 1995) whereas plants with a mutant $\angle F Y$ gene bear leaves and associated shoot instead of flowers (Weigel et al., 1992) showing that LFY participates in determining the flowering time. Flower-like structures eventually appear on a /fy "inflorescence" because the FMI gene APETALA1 can be activated in an LFY-independent manner and partially compensates for the lack of $\angle F Y$ (Bowman et al., 1993, Huala and Sussex, 1992, Weigel and Meyerowitz, 1994).

LFY expression persists throughout young floral meristems where it contributes to the specification of the young floral buds by, for instance, inducing the AP1 and CAL (Parcy et al., 1998, Wagner and Meyerowitz, 2002, Wagner et al., 2004), to the floral

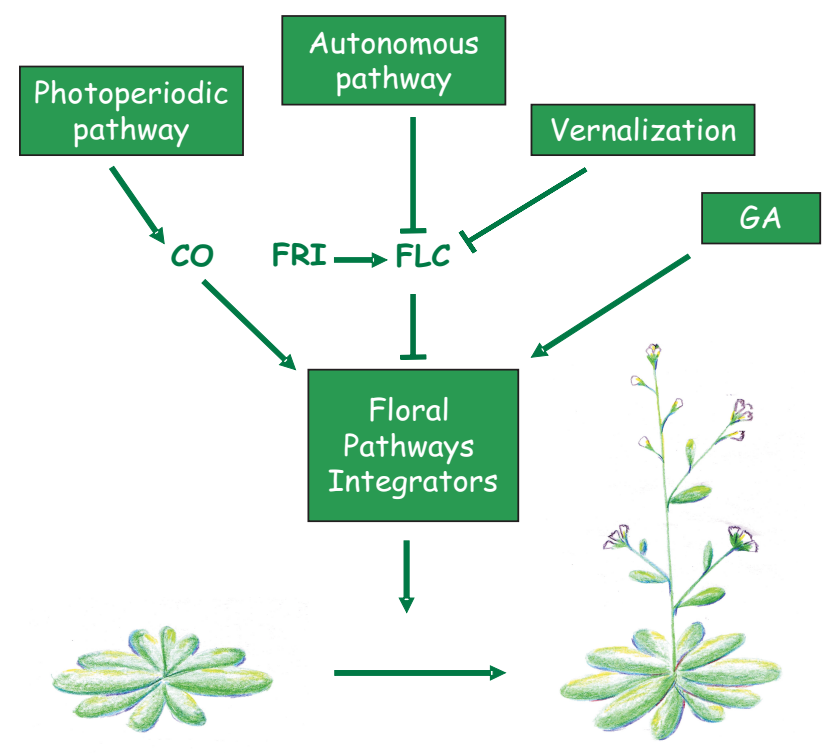

Fig. 1. Main pathways reaching Floral Pathways Integrators meristem patterning (Lohmann et al., 2001, Parcy et al., 1998) and to the repression of shoot identity (Parcy et al., 2002, Yu et al., 2004).

$\angle F Y$ encodes a new type of plant specific transcription factor (Parcy et al., 1998, Weigel et al., 1992). The LFY protein appears to be localized primarily in the nucleus (Parcy et al., 1998, Wagner et al., 1999, Wu et al., 2003) but LFY-GFP fusion proteins also accumulate in the cytoplasm and the plasmodesmatal pit $\mathrm{Wu}$ et al., 2003). LFY is able to travel from one cell to another through plasmodesmata but the functional importance of this movement awaits confirmation (Sessions et al., 2000). The LFY protein has been shown to bind cis-elements present in AP1 and AGAMOUS (AG) regulatory sequences (Busch et al., 1999, Lohmann et al., 2001, Parcy et al., 1998). LFY activity appears to be modulated by day-length since plants constitutively expressing $\angle F Y$ flower later in short days (SD) than in long days (LD), but how photoperiod affects $\angle F Y$ is still unknown (Nilsson et al., 1998, Weigel and Nilsson, 1995).

\section{Flowering locus $T$ (FT)}

The FT gene was simultaneously isolated using an earlyflowering activation-tagged allele and a late-flowering T-DNA mutant (Kardailsky et al., 1999, Kobayashi et al., 1999). The ft mutant is late in LD conditions and only slightly affected in SD, indicating that FT belongs to the photoperiod pathway (Koornneef et al., 1991). As opposed to other flowering time mutations, the $f t$ mutation strongly enhances the Ify mutant phenotype (RuizGarcia et al., 1997) and efficiently suppresses the 35S::LFY early flowering phenotype (Nilsson et al., 1998). For this reason, FT was assigned to a separate branch of the photoperiod pathway together with $F W A$ and $F D$. FT encodes a protein with similarities to Phosphatidylethanolamine binding protein (PEBP) and Raf kinase inhibitor protein (RKIP) in animals (Kardailsky etal., 1999, Kobayashi etal., 1999), but its function in plants remains to be identified. Using the sensitive RT-PCR technique, FT expression was detected in all organs (Kardailsky et al., 1999, Kobayashi et al., 1999). Remarkably, FT mRNA levels in seedlings increases during vegetative growth in LD, reaching its maximum around the floral transition. FT expression is reduced in SD but still shows a clear increase with time. Low expression levels have precluded a precise analysis of FT expression pattern by in situ hybridization. The FT::GUS reporter gene shows expression primarily in phloem cells of the leaves and shoot (Takada and Goto, 2003). FT constitutive expression is very potent at accelerating flowering both in LD and SD. The fastest flowering is obtained by combining constitutive expression of $F T$ and $\angle F Y$ : plants produce flowers after forming only one or two leaves in LD (Kardailsky et al., 1999, Kobayashi et al., 1999).

\section{Suppressor of CO overexpression (SOC1)/AGAMOUS-like 20 (AGL20)}

SOC1/AGL20 encodes a MADS box transcription factor. Surprisingly, the soc1 mutant was not isolated in standard genetic screens for late flowering mutants. It came out independently in a screen for suppressor of CONSTANS overexpression (Onouchi et al., 2000, Samach et al., 2000), from an activation tagging screen in the FRIGIDA (FRI) FLC background (Lee et al., 2000) and using reverse genetics (Borner et al., 2000). Soc1 mutant flowers late in both LD and SD (Borner et al., 2000, Lee et al., 2000). SOC1 is 
expressed mostly in leaves and in the shoot apex, its expression raises with time and a sharp increase occurs in the apex during the floral transition (Borner et al., 2000, Lee et al., 2000, Samach et al., 2000). SOC1 expression is absent from stage 1 flower meristem and reappears in the center of older flower meristems (Figure 2).

\section{Regulation of floral pathway integrator expression}

LFY, SOC1 and FT have recently been referred to as Floral Pathway Integrators (Simpson and Dean, 2002) because they represent convergence nodes for several promotion pathways: the photoperiod pathway through the action of its most downstream "specific" element $\mathrm{CO}$, the vernalization and autonomous pathways through the action of the FLC repressor and the GA pathway. FLC itself could also be considered as an integrator. However, we will stick to the initial definition as proposed by Simpson et al. (2002). It is worth pointing out here that the evidence for integrated regulation is derived essentially from integrators expression at the mRNA level. The three integrators proteins might also be regulated at many other post-transcriptional levels that have been poorly investigated so far.

\section{Regulation by CONSTANS (CO)}

The $C O$ gene plays a key role in the photoperiod pathway. $C O$ mRNA level oscillates following a circadian rhythm and the $\mathrm{CO}$ protein is stabilized by light (Suarez-Lopez et al., 2001, Valverde et al., 2004). In LD, CO mRNA expression and CO protein stability coincide at dusk and the $\mathrm{CO}$ protein accumulates to accelerate flowering. In SD, this coincidence does not occur and the CO protein never accumulates. This mechanism elegantly explains why co mutant flowers late in LD but as the wild type in SD.

A whole set of data shows that $\mathrm{CO}$ triggers flowering by inducing the 3 integrators. $\angle F Y$ and $F T$ expression are reduced in $c o$ mutant (Kardailsky etal., 1999, Kobayashi etal., 1999, Nilsson etal., 1998, Suarez-Lopez et al., 2001). SOC1 expression, also, might be slightly reduced (Lee et al., 2000). In addition, the late flowering phenotype of the co mutant is rescued by overexpression of $F T$ (complete rescue), SOC1 (rescue almost complete) or $\angle F Y$ (partial rescue) (Kardailsky et al., 1999, Kobayashi et al., 1999, Nilsson et al., 1998, Samach et al., 2000). These data suggest CO positively regulates $\angle F Y, F T$ and SOC1 (Figure 3). This hypothesis was largely confirmed by gain-of-function experiments. Constitutive overexpression of $\mathrm{CO}$ (or of the inducible CO-GR fusion) induces early flowering and increases the expression of $F T, S O C 1$ and $\angle F Y$ (Samach et al., 2000, Simon et al., 1997). Induction of SOC1 and FT are rapid (a few hours) and direct (without intermediate translation step), whereas $\angle F Y$ induction takes one day suggesting that it might be more indirect (Samach et al., 2000). Both SOC1 and $\mathrm{ft}$ mutations delay flowering of $35 \mathrm{~S}: \mathrm{CO}$ plants confirming that $\mathrm{CO}$ acts through FT and SOC1 induction (Onouchi et al., 2000, Samach et al., 2000, Suarez-Lopez et al., 2001). Its worth pointing out that the expression of the 3 integrators is still upregulated in the $c 0$ mutant, indicating that $\mathrm{CO}$ is no the only factor responsible for their induction.

$\mathrm{CO}$ encodes a nuclear zinc finger containing protein, a potential transcription factor, but the precise mechanism of $\mathrm{CO}$ action is not yet understood (Putterill et al., 1995). In particular, CO has not been shown to bind DNA and is, therefore, assumed to be tethered to regulatory sequences through interaction with other (unknown)
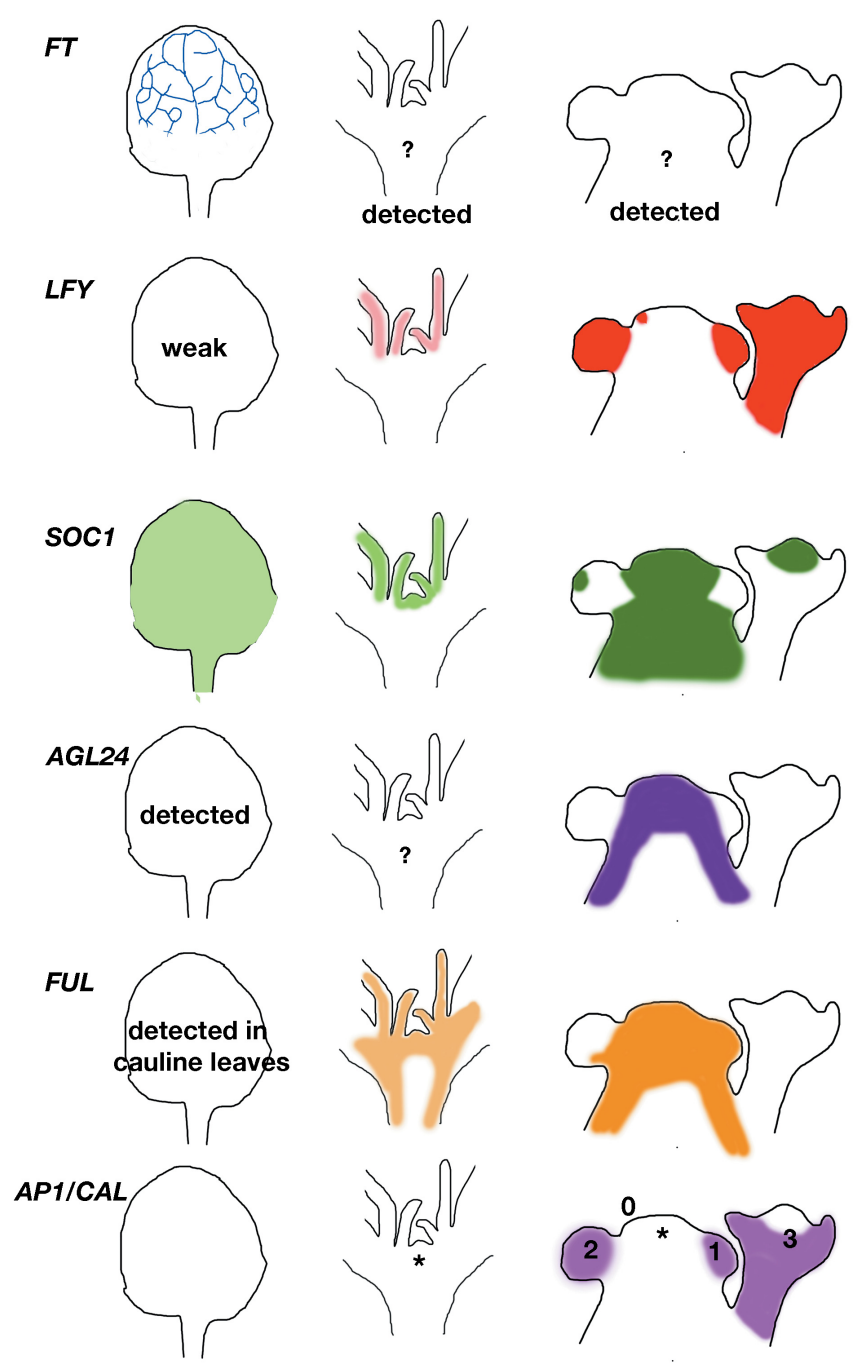

Fig. 2. Rough expression patterns of some integrators and some other important regulators. A leaf, a vegetative and a reproductive apex are depicted. Color represent mRNA (or promoter::GUS) expression patterns for the genes indicated. "Detected" means the expression has been detected by RT-PCR or Northern analysis but the expression pattern is not known. A change in color brightness (as for AGL24, SOC1 and"FUL) indicates an increased expression upon floral transition. The star indicates the shoot apical meristem, the numbers indicate floral meristem stages (Smyth et al., 1990). AGL24 expression has also been found in outer layers of early floral stages (Yu et al., 2004).

transcription factors (Hepworth et al., 2002). The precise analysis of $C O$ expression pattern has recently led to new and exciting questions regarding CO mode of action (An et al., 2004, Takada and Goto, 2003). Indeed, the photoperiodic signal was known to be perceived in leaves and somehow transmitted to the apex by the unknown florigen signal (Bernier et al., 1993, Colasanti and Sundaresan, 2000, Zeevaart, 1976). The discovery that CO is expressed in the vascular system of the leaves (in the phloem companion cells) and induces $F T$ in this tissue, suggests that the florigen signal is downstream or at the same level as $C O$ (An et al., 2004, Takada and Goto, 2003). Expression of $C O$ from different promoters showed that $\mathrm{CO}$ triggers early flowering when ex- 
pressed in the leaf phloem but not in the apex (An etal., 2004, Ayre and Turgeon, 2004). These experiments nicely suggested that $\mathrm{CO}$ acts from the leaves and that the florigen is downstream of $C O$. As opposed to $C O$, its target gene $F T$ can trigger early flowering when expressed either from the leaves or from the apex, suggesting either that FT itself is the florigen or that FT can induce the florigen synthesis both from leaves and the apex. The possibility that $\mathrm{CO}$ would need to travel to the apex and be modified on its way has also been proposed (Ayre and Turgeon, 2004) but requires further investigations. Why $\mathrm{CO}$ cannot trigger early flowering when expressed from the apex is not understood. CO might require a leaf coregulator (maybe its DNA binding partner), absent from the apex and necessary to induce SOC1 and FT. This hypothesis could be easily tested by analyzing whether the increased FT::GUS expres-

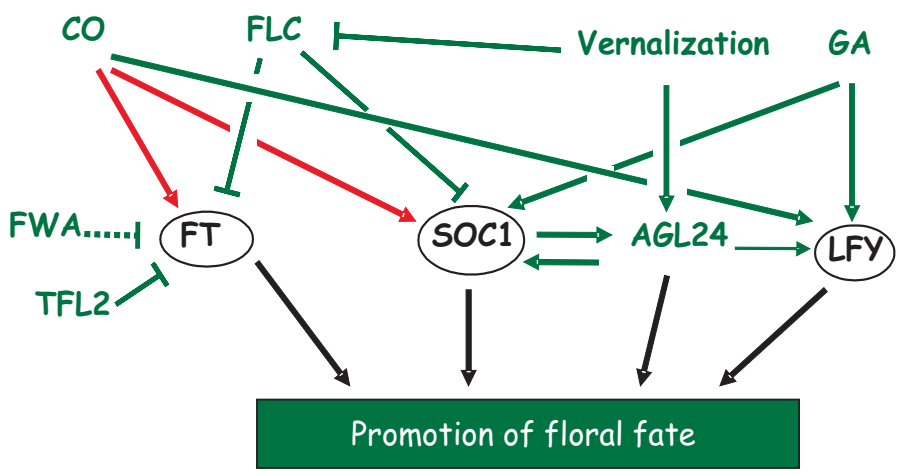

Fig. 3. Gene regulatory network around Floral Pathway Integrators. Red arrows represent direct interactions, dashed arrows represent posttranscriptional regulation and plain arrows represent transcriptional regulation. Floral Pathway Integrators are circled.

sion of 35S::CO plants invades the shoot apical meristem (Takada and Goto, 2003).

Knowing that $\mathrm{CO}$ acts from the leaves to induce $F T$ also raises many questions about the induction of SOC1 and $\angle F Y$. Both $\angle F Y$ and $S O C 1$ expression increase at the apex during the floral transition ( $S O C 1$ in the apex itself and $\angle F Y$ in the flower anlagen). $\angle F Y$ could be induced indirectly (for instance through SOC1- see later) but SOC1 has been shown to be a direct target of $\mathrm{CO}$ in 35S::CO-GR plants (Samach et al., 2000). However, in most published reports, SOC1 expression or SOC1 promoter activation has been analyzed in whole seedlings without precise characterization of the induction in the apex (Hepworth et al., 2002, Lee et al., 2000). The limitation of this type of analyses appears in situations where there is no correlation between the global expression level of SOC1 or FT and flowering time (Hepworth et al., 2002). Precisely characterizing where does CO induce SOC1 during the transition of wild type plants and from where SOC1 is able to trigger flowering would be important to understand whether SOC1 also might be part of the florigen signal.

\section{Regulation by FLC}

FLC plays a major role in repressing flowering in Arabidopsis (Michaels and Amasino, 1999). It is the convergence point of the autonomous and the vernalization pathways (Figure 1) and is also regulated by other genes such as FRI, ELF5 or PIE (Michaels and Amasino, 1999, Noh and Amasino, 2003, Noh et al., 2004).
Differences in $F L C$ and $F R /$ sequence or expression account for a lot of the natural variation between Arabidopsis accessions (Johanson et al., 2000, Michaels et al., 2003b). To accelerate flowering, the autonomous and the vernalization promotion pathways repress $F L C$ and maintain it in a repressed state using various epigenetic mechanisms (Bastow et al., 2004, He et al., 2003, Sung and Amasino, 2004b).

Several types of evidence show that FLC acts by repressing the integrators FT and SOC1: i) FLC is necessary for the downregulation of SOC1 occurring in autonomous pathway mutants (Michaels and Amasino, 1999, Samach et al., 2000). ii) SOC1 is repressed in 35S::FLC transgenic plants (Michaels and Amasino, 1999) iii) Both SOC1 and FT are upregulated in an flc null mutant (Moon et al., 2003). We do not know exactly from which part of the plant FLC acts. Vernalization has been shown to be perceived at the shoot apex (Amasino, 2004) and FLC is expressed mainly in shoot and root apices but its mRNA is also detectable in leaves (He etal., 2003, Michaels and Amasino, 1999). It will be interesting to determine whether FLC represses FT and SOC1 from the leaves (where CO induces $F T$ ) or from the apex. So far, there is no clear evidence that FLC also directly affects $\angle F Y$ expression. However, late flowering mutants of the autonomous pathway, $L F Y$ expression is decreased and this effect is probably mediated through FLC (Nilsson et al., 1998).

FLC encodes a MADS-box factor and has been shown to bind to regulatory sequences of SOC1 necessary for its repression in leaves (Hepworth et al., 2002). However, as pointed out before, this repression has mainly been studied in leaves where its relevance remains to be established (Hepworth et al., 2002).

\section{Regulation by $G A$}

As attested by GA biosynthetic and response mutants, GA is crucial to promote flowering mainly in short day conditions. The ga1 biosynthetic mutant flowers extremely late (sometimes never) in SD (Blazquez et al., 1998, Wilson et al., 1992). GA acts, at least in part, by upregulating' $\angle F Y: \angle F Y$ expression is dramatically reduced in ga1 mutant in SD and constitutive expression of $\angle F Y$ is sufficient to rescue the late flowering of this mutant (Blazquez et al., 1998). A cis-element has been found in the $\angle F Y$ promoter that abolishes its response to $\mathrm{GA}$ without affecting $\angle F Y$ induction by photoperiod, indicating that the two different pathways are integrated at the level of $\angle F Y$ promoter (Blazquez and Weigel, 2000). This cis-element resembles a MYB factor binding site and interacts with the AtMYB33 protein in vitro (Gocal et al., 2001) but the identity of the transcription factor responsible for $\angle F Y$ induction by $G A$ remains to be firmly established.

GA is also involved in inducing SOC1 expression (Moon et al., 2003) and maybe also FT. This last point has not been demonstrated but, in SD, GA are required for flowering and $F T$ displays a peak of expression (albeit lower as in LD), suggesting GA might be responsible for FT induction in these growth conditions. Also, early flowering of the ebs mutant is dependent on GA and EBS represses $F T$, again suggesting that GA might be responsible for FT derepression in the ebs mutant (Gomez-Mena et al., 2001, Pineiro et al., 2003).

As for $\mathrm{CO}$ action, it will be important to determine from where the GA signal originates and what are the steps leading to $L F Y$ upregulation. In short days, the concentration of the active gibberellin GA4 increases dramatically prior to floral initiation but this 
increase appears to be caused by a transport of GAs into the apex (maybe from the leaves) (O. Nilsson pers. com.).

\section{Additional levels of regulation}

Although they are not clearly assigned to one of the main pathways, some other regulators have been shown to regulate the integrators expression or activity. Two potential chromatin-remodeling factors participate to $F T$ repression. TFL2 (also called LHP1) is a heterochromatin protein counteracting $F T$ induction by $\mathrm{CO}$ (Gaudin et al., 2001, Kotake et al., 2003, Takada and Goto, 2003). EBS is a nuclear protein containing a bromoadjacent homology domain repressing FT (Gomez-Mena et al., 2001, Pineiro et al., 2003). The homeobox gene $F W A$ also appears to counteract FT as revealed by suppression of early-flowering phenotype of $F T$ over-expression by the late-flowering fwa mutation (Kardailsky et al., 1999; Kobayashi et al., 1999). It has been shown that FWA is ectopically expressed due to hypomethylation in promoter repeats in semi-dominant fwa plants (Soppe et al., 2000). However, the relevance of FWA action in a wild-type context has yet been elucidated.

\section{Interactions between integrators}

The integrators are not only affected by the same set of pathways but they also appear to be linked to each other, thereby forming an intricate gene regulatory network (Figure 3 ).

\section{Links between FT and LFY}

$\angle F Y$ expression was initially thought to be largely independent from FT. In leaf primordia of the $f t$ mutant, the $\angle F Y:: G U S$ reporter gene is expressed normally ( $\angle F Y$ mRNA levels have not been analyzed) (Nilsson et al., 1998). However, recent evidence suggests that FT might be able to induce $\angle F Y$. $\angle F Y$ was indeed found to be downregulated in $\mathrm{ft}$ mutant plants grown in SD and shifted to LD. The difference is already obvious before the shift, suggesting that $\mathrm{FT}$ is involved in $\angle F Y$ progressive upregulation (Schmid et al., 2003). Also, in 35S.:FT plants, $L F Y$ is ectopically expressed in the apical meristem and a terminal flower forms (Kardailsky et al., 1999). In this later case, the $\angle F Y$ induction might be indirect. Indeed, in wild-type plants, $L F Y$ expression normally does not enter the shoot apical meristem because it is repressed by TERMINAL FLOWER1 (TFL1) (Ratcliffe et al., 1998). Since TFL1 encodes an FT homolog (but with opposite function), it is conceivable that an excess of FT would compete with TFL1, thereby preventing it to repress $\angle F Y$ in the apex.

\section{Links between SOC1 and FT}

In an $f t$ mutant, SOC1 upregulation in the apex after a shift from $\mathrm{SD}$ to $\mathrm{LD}$ is reduced, suggesting that FT might participate in the control of SOC1 expression (Schmid et al., 2003). However this difference might just be a consequence of the delayed flowering of the ft mutant. Therefore, the relationship between SOC1 and FT requires further investigation.

\section{Links between SOC1 and LFY}

SOC1 has been propose to induce $\angle F Y$ (Jack, 2004, Lee et al., 2000, Mouradov et al., 2002). However there is still little data to support this attractive hypothesis. Conversion of axillary inflorescences into solitary flowers in plants overexpressing SOC1 sug- gests $\angle F Y$ might be ectopically expressed in response to SOC1 (Lee et al., 2000). However, LFY expression has been studied neither in SOC1 mutant nor in plants overexpressing SOC1.

One scenario has been proposed in which $A G L 24$ would serve as an intermediate between SOC1 and $\angle F Y$ (Yu et al., 2002). $A G L 24$ encodes a MADS box protein and is expressed at the shoot apex with a sharp increase at the time of floral transition (Michaels et al., 2003a, Yu et al., 2002) (Figure 2). The agl24 mutant is late flowering in both LD and SD and overexpressing AGL24 leads to early flowering (Michaels et al., 2003a, Yu et al., 2002). AGL24 is also induced by vernalization and might participate in the FLCindependent vernalization effect (Michaels et al., 2003a). AGL24 has been suggested to act downstream of SOC1 because AGL24 expression is decreased in soc1 mutant (and also in $c 0$ ) (Yu et al., 2002). However, there is no consensus regarding the ability of AGL24 constitutive expression to rescue the soc 1 mutant (Michaels et al., 2003a, Yu et al., 2002). In addition, AGL24 is also able to induce SOC1 expression (Michaels et al., 2003a). Understanding the interactions between SOC1 and $A G L 24$ clearly requires additional work. Given that overexpression of one of the two genes has little effect when the other one is mutated (Michaels et al., 2003a), one can also imagine that the two proteins works together in a MADS box complex capable of autoregulation, similar to the AP3/PI complex (Krizek and Meyerowitz, 1996).

AGL24 has been suggested to regulate $\angle F Y$ expression ( $Y u$ et al., 2002). $\angle F Y$ expression is reduced in ag/24 mutant at the time the wild type plant flowers. In addition, agl24 mutation do not delay flowering when $\angle F Y$ is expressed constitutively suggesting that AGL24 acts by upregulating $\angle F Y$. It would be interesting to confirm this hypothesis by analyzing $\angle F Y$ expression before the floral transition, in order to demonstrate that reduced $\angle F Y$ expression is not just a simple consequence of agl24 late flowering.

The linear cascade from SOC1 to $\angle F Y$ through $A G L 24$ is simple and attractive. However, it requires further work to be demonstrated and will not be sufficient to explain observed phenotypes. LFY expression is not abolished in soc1 or ag/24 mutants, AGL24 not abolished in soc1 mutant, indicating that other factors contribute to the upregulation of $\angle F Y$ or $A G L 24$. The existence of functional redundancy between MADS-box genes might help explaining this complex situation. It is indeed quite remarkable that the three 3 MADS box genes SOC1, AGL24 and FRUITFULL (FUL ) are expressed with an overlapping expression pattern (Figure 2) and all trigger early flowering when overexpressed (Ferrandiz et al., 2000b, Lee et al., 2000, Michaels et al., 2003a, Yu etal., 2002). FUL has received less attention probably because the ful single mutant is only slightly late flowering (Ferrandiz et al., 2000a). Combining mutations in these three genes might reveal new roles

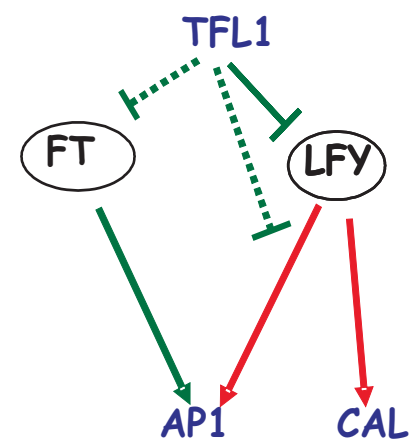

Fig. 4. From Integrators to activation of $A P 1$ and $C A L$. Red arrows represent direct interactions, dashed arrows representpost-transcriptional regulation and plain arrows represent transcriptional regulation. 
that were not obvious from single mutant analysis. It is also possible that some of these proteins participate in heterotetrameric complexes of MADS-box genes as for floral organ identity determination (Honma and Goto, 2001). The existence of such complexes made of combination of not only activators but also of repressors (such as SVP, FLC, FLMIMAF1 or MAF2-5) might provide an exquisite way to regulated flowering in response to a balance of stimulations (Hartmann et al., 2000, Ratcliffe et al., 2003, Scortecci et al., 2003, Scortecci et al., 2001).

\section{Downstream of the integrators}

Once FT, SOC1 and $\angle F Y$ have been turned on, flowering occurs. Constitutive expression of single or pairs of these integrators is already very potent at inducing 'immediate' flowering after germination. What are the molecular events initiated by the presence of floral integrators? One obvious consequence is $A P 1$ and $C A L$ induction. However, since $A P 1$ overexpression is not as potent as SOC1 or LFYIFT overexpression, it is likely that many more molecular events are initiated. Several recent studies at the whole genome scale identified $\angle F Y, F T, C O$ induced genes or LFY direct targets (Schmid et al., 2003, Wagner et al., 2004, William et al., 2004). Analyzing the function of all these genes will represent of large amount of work but will certainly increase our knowledge on molecular events occurring during flowering.

\section{Regulation of AP1/CAL by LFY}

$A P 1$ and $C A L$ are expressed after $\angle F Y$ in the stage 1 floral meristem. In an ap1/cal double mutant, stage 1 and 2 flower meristems form but loose their floral fate (Bowman et al., 1993). A convincing set of evidence shows that $A P 1$ is a direct target of LFY. a) $A P 1$ and $C A L$ are activated in stage 1 floral meristem (figure 2), in a subpart of the domain expressing $\angle F Y$ (Kempin et al., 1995, Mandel et al., 1992). b) In a /fy mutant, $A P 1$ expression is strongly delayed and, in 35S::LFY plants, $A P 1$ expression occurs earlier (in floral buds) but also in leaf primordia (Liljegren et al., 1999, Parcy et al., 1998, Ruiz-Garcia et al., 1997, Weigel and Meyerowitz, 1993). c) The use of an inducible $\angle F Y: G R$ fusion demonstrated that $A P 1$ and $C A L$ induction by LFY does not require an intermediate translational step and that the LFY protein binds to sequences present in the AP1 promoter (Parcy et al., 1998, Wagner et al., 1999, William et al., 2004). d) Recently, LFY binding in vivo to $A P 1$ and $C A L$ regulatory sequences was demonstrated by chromosome immunoprecipitation (William et al., 2004).

Several points still remain to be understood. The importance of these LFY binding sites in the $A P 1$ and $C A L$ promoters has not yet been tested. In addition, it is known that LFY is not sufficient to activate $A P 1$ on its own. In yeast, LFY requires an activation domain to activate the $A P 1$ promoter (Parcy etal., 1998). In plants also, $\angle F Y$ or $\angle F Y$-GR constitutive expression does not constitutively induce AP1 (Parcy et al., 1998, Wagner et al., 1999). LFY therefore probably needs a co-regulator to induce $A P 1$ and $C A L$. This coregulator could be a protein binding next to LFY (such as WUSCHEL (WUS) for AGAMOUS regulation (Lohmann et al., 2001)) or a coactivator recruited by LFY at the $A P 1$ promoter.

\section{Regulation of AP1 by FT}

As mentioned earlier, AP1 can be induced independently of
LFY. Flower like structures eventually form on a /fy mutant and not on a Ify ap 1 double (Huala and Sussex, 1992, Weigel etal., 1992). The $A P 1$ expression occurring in a lfy mutant is absent from a $f t$ Ify double mutant showing that FT is able to induce $A P 1$ independently of LFY (Ruiz-Garcia et al., 1997). How FT induces $A P 1$ is not yet understood. Also, whereas $C A L$, as $A P 1$, appears to be regulated by LFY, it is unclear why it cannot compensate for the loss of $A P 1$ in Ify ap1 double mutant. This observation might indicate that FT is not able to induce $C A L$ independently of LFY, or that $C A L$ and AP1 meristem identity functions are not exactly equivalent.

\section{A synergistic action of LFY and FT?}

Genetic data clearly illustrate that FT is able to induce $A P 1$ independently of LFY. However, it does not necessarily mean that FT does so during the wild-type floral transition. On the contrary, both FT and LFY appear required for the initial $A P 1$ induction: $A P 1$ induction is delayed in both the /fy and the $\mathrm{ft}$ single mutants suggesting that $\angle F Y$ and $F T$ rather act synergistically. The FT pathway might actually represent the previously postulated LFY coregulator for AP1 activation. A parallel with AG activation by LFY plus WUS can be drawn where LFY and WUS are thought to act synergistically in the wild type plant but still, each of them is able to induce $A G$ independently of the other (Lohmann et al., 2001). What is the molecular basis for LFY and FT synergistic action remains to be understood.

Interestingly, there are indications that TFL 1, which encodes a homolog of FT with opposite function (Bradley et al., 1996, Ratcliffe et al., 1998) might also influence LFY capacity to induce $A P 1$. TFL1 counteracts LFY in different ways. It prevents $\angle F Y$ expression from entering the shoot apex. In addition, when TFL 1 is constitutively expressed, LFY appears less efficient at inducing $A P 1$ and the $F T$-dependent $A P 1$ induction also does not occur (Ratcliffe et al., 1999). FT and TFL1 proteins might compete antagonistically to control $A P 1$ upregulation by LFY. Deciphering FT and TFL1 mode of action at the molecular level is a major challenge to our understanding of floral commitment and the interplay between meristem identity genes.

\section{Conclusion}

Tremendous progress has been realized in the last 20 years thanks to Arabidopsis genetics. After a flurry of mutant isolations, organization into a few separate pathways, cloning of the genes and analysis of their molecular function, the current picture is very different from the one two decades ago. Initially, mutations affecting "specifically" one of the pathways were the most attractive. A new class of genes has arisen that stand at the crossroads between the different pathways and integrate the influence of the environment to control the expression and activity of the floral meristem identity genes. As we pursue expression analyses, it is likely that more cross-talks between the pathways will be revealed even if they could not be guessed from genetic analyses. Progressively, the linear pathways are being integrated into a (much more realistic) gene regulatory network. Also, whereas a major focus has been initially put on gene expression at the mRNA level (probably because these experiments are the most straightforward once the gene is cloned), it is likely that analysis of protein expression and activity will reveal new links. The simple arrows 
present in current models will soon become insufficient to account for the network complexity.

Also, as mentioned all along this review, the spatial aspects of the regulations have become increasingly important and analyses at the whole seedling level, as they have been performed so far, should be carefully revisited in order to draw a much more accurate picture. For instance, $\mathrm{CO}$ direct target genes identified using whole seedlings constitutively expressing $C O$, do not appear to be $\mathrm{CO}$ target in the apex during the floral transition (Samach et al., 2000, Schmid et al., 2003). The early distinction made between flowering time genes and meristem identity genes has been very useful in structuring the field and making it easier to follow from outside. With genes like TFL1 or $L F Y$, the frontiers have been fading and loosing part of their significance. Today, to build the gene regulatory network and understand the nature of interactions between regulators, it might be more helpful to classify proteins according to their site of action (leaf, apex, early floral meristem), even if some of them will belong to several groups. Finally, many changes occurring during flowering such as bolting or changes in phyllotaxy will have to be integrated in the global scheme.

\section{Acknowledgments}

I am very grateful to $O$. Nilsson for inspiring discussions and precious feedback. I would like to thank T. Araki and $O$. Nilsson for reviewing this review, M. Blazquez, D. Weigel, C. Ferrandiz, P. Madueño, T. Araki, P. Wigge and M.C. Kim for fruitful discussions and Bab. Martin for kindly drawing plants of Figure 1.

\section{References}

AMASINO, R. (2004). Vernalization, competence, and the epigenetic memory of winter. Plant Cel/16, 2553-2559.

AN, H., ROUSSOT, C., SUAREZ-LOPEZ, P., CORBESIER, L., VINCENT, C., PINEIRO, M., HEPWORTH, S., MOURADOV, A., JUSTIN, S., TURNBULL, C., and COUPLAND, G. (2004). CONSTANS acts in the phloem to regulate a systemic signal that induces photoperiodic flowering of Arabidopsis. Development 131, 3615-3626.

ARAKI, T. (2001). Transition from vegetative to reproductive phase. Curr Opin Plant Bio/4, 63-68.

AYRE, B.G., and TURGEON, R. (2004). Graft transmission of a floral stimulant derived from CONSTANS. Plant Physiol 135, 2271-2278.

BASTOW, R., and DEAN, C. (2003). Plant sciences. Deciding when to flower. Science 302, 1695-1696.

BASTOW, R., MYLNE, J.S., LISTER, C., LIPPMAN, Z., MARTIENSSEN, R.A., and DEAN, C. (2004). Vernalization requires epigenetic silencing of $F L C$ by histone methylation. Nature 427, 164-167.

BERNIER, G., and PÉRILLEUX, C. (2005). A physiological overview of the genetics of flowering time control. Plant Biotechnology Journal 3, 3-16.

BERNIER, G., HAVELANGE, A., HOUSSA, C., PETITJEAN, A., and LEJEUNE, P. (1993). Physiological signals that induce flowering. Plant Cell 5, 1147-1155.

BLAZQUEZ, M.A., and WEIGEL, D. (2000). Integration of floral inductive signals in Arabidopsis. Nature 404, 889-892.

BLAZQUEZ, M.A., SOOWAL, L.N., LEE, I., and WEIGEL, D. (1997). LEAFY expression and flower initiation in Arabidopsis. Development 124, 3835-3844.

BLAZQUEZ, M.A., GREEN, R., NILSSON, O., SUSSMAN, M.R., and WEIGEL, D. (1998). Gibberellins promote flowering of Arabidopsis by activating the $\angle E A F Y$ promoter. Plant Cell 10, 791-800.

BORNER, R., KAMPMANN, G., CHANDLER, J., GLEISSNER, R., WISMAN, E., APEL, K., and MELZER, S. (2000). A MADS domain gene involved in the transition to flowering in Arabidopsis. Plant J 24, 591-599.
BOSS, P.K., BASTOW, R.M., MYLNE, J.S., and DEAN, C. (2004). Multiple pathways in the decision to flower: enabling, promoting, and resetting. Plant Cell 16 Suppl, S18-31.

BOWMAN, J.L., ALVAREZ, J., WEIGEL, D., MEYEROWITZ, E.M., and SMYTH, D.R. (1993). Control of flower development in Arabidopsis thalianaby APETALA1 and interacting genes. Development 119, 721-743.

BRADLEY, D., CARPENTER, R., COPSEY, L., VINCENT, C., ROTHSTEIN, S., and COEN, E. (1996). Control of inflorescence architecture in Antirrhinum. Nature 379, 791-797.

BUSCH, M.A., BOMBLIES, K., and WEIGEL, D. (1999). Activation of a floral homeotic gene in Arabidopsis. Science 285, 585-587.

COLASANTI, J., and SUNDARESAN, V. (2000). 'Florigen' enters the molecular age: long-distance signals that cause plants to flower. Trends Biochem Sci 25, 236-240.

FERRANDIZ, C., LILJEGREN, S.J., and YANOFSKY, M.F. (2000a). Negative regulation of the SHATTERPROOFgenes by FRUITFULL during Arabidopsis fruit development. Science 289, 436-438.

FERRANDIZ, C., GU, Q., MARTIENSSEN, R., and YANOFSKY, M.F. (2000b). Redundant regulation of meristem identity and plant architecture by FRUITFULL, APETALA1 and CAULIFLOWER. Development 127, 725-734.

GAUDIN, V., LIBAULT, M., POUTEAU, S., JUUL, T., ZHAO, G., LEFEBVRE, D., and GRANDJEAN, O. (2001). Mutations in LIKE HETEROCHROMATIN PROTEIN 1 affect flowering time and plant architecture in Arabidopsis. Development 128, 4847-4858.

GOCAL, G.F., SHELDON, C.C., GUBLER, F., MORITZ, T., BAGNALL, D.J., MACMILLAN, C.P., LI, S.F., PARISH, R.W., DENNIS, E.S., WEIGEL, D., and KING, R.W. (2001). GAMYBlike genes, flowering, and gibberellin signaling in Arabidopsis. Plant Physiol 127, 1682-1693.

GOMEZ-MENA, C., PINEIRO, M., FRANCO-ZORRILLA, J.M., SALINAS, J., COUPLAND, G., and MARTINEZ-ZAPATER, J.M. (2001). early bolting in short days: an Arabidopsis mutation that causes early flowering and partially suppresses the floral phenotype of leafy. Plant Cell 13, 1011-1024.

HARTMANN, U., HOHMANN, S., NETTESHEIM, K., WISMAN, E., SAEDLER, H., and HUIJSER, P. (2000). Molecular cloning of SVP. a negative regulator of the floral transition in Arabidopsis. Plant J 21, 351-360.

HE, Y., MICHAELS, S.D., and AMASINO, R.M. (2003). Regulation of flowering time by histone acetylation in Arabidopsis. Science 302, 1751-1754.

HEMPEL, F.D., and FELDMAN, L.J. (1993). Bi-directional inflorescence development in Arabidopsis thaliana. Acropetal initiation of flowers and basipetal initiation of paraclades. Planta 192, 276-286.

HENDERSON, I.R., and DEAN, C. (2004). Control of Arabidopsisflowering: the chill before the bloom. Development 131, 3829-3838.

HEPWORTH, S.R., VALVERDE, F., RAVENSCROFT, D., MOURADOV, A., and COUPLAND, G. (2002). Antagonistic regulation of flowering-time gene SOC1 by CONSTANS and FLC via separate promoter motifs. Embo J 21, 4327-4337.

HONMA, T., and GOTO, K. (2001). Complexes of MADS-box proteins are sufficient to convert leaves into floral organs. Nature 409, 525-529.

HUALA, E., and SUSSEX, I.M. (1992). LEAFY interacts with Floral Homeotic genes to regulate Arabidopsis floral development. Plant Cell 4, 901-903.

JACK, T. (2004). Molecular and genetic mechanisms of floral control. Plant Cell 16 Suppl, S1-17.

JOHANSON, U., WEST, J., LISTER, C., MICHAELS, S., AMASINO, R., and DEAN, C. (2000). Molecular analysis of $F R / G I D A$, a major determinant of natural variation in Arabidopsis flowering time. Science 290, 344-347.

KARDAILSKY, I., SHUKLA, V.K., AHN, J.H., DAGENAIS, N., CHRISTENSEN, S.K., NGUYEN, J.T., CHORY, J., HARRISON, M.J., and WEIGEL, D. (1999). Activation tagging of the floral inducer FT. Science 286, 1962-1965.

KEMPIN, S.A., SAVIDGE, B., and YANOFSKY, M.F. (1995). Molecular basis of the cauliflowerphenotype in Arabidopsis. Science 267, 522-525.

KIEFFER, M., and DAVIES, B. (2001). Developmental programmes in floral organ formation. Semin Cell Dev Biol 12, 373-380.

KOBAYASHI, Y., KAYA, H., GOTO, K., IWABUCHI, M., and ARAKI, T. (1999). A pair of related genes with antagonistic roles in mediating flowering signals. Science 286, 1960-1962. 
KOORNNEEF, M., HANHART, C.J., and VAN DER VEEN, J.H. (1991). A genetic and physiological analysis of late flowering mutants in Arabidopsis thaliana. Mol. Gen. Genet. 229, 57-66.

KOTAKE, T., TAKADA, S., NAKAHIGASHI, K., OHTO, M., and GOTO, K. (2003). Arabidopsis TERMINAL FLOWER 2 gene encodes a HETEROCHROMATIN PROTEIN 1 homolog and represses both FLOWERING LOCUS Tto regulate flowering time and several floral homeotic genes. Plant Cell Physiol 44, 555564.

KRIZEK, B.A., and MEYEROWITZ, E.M. (1996). The Arabidopsis homeotic genes APETALA3 and PISTILLATA are sufficient to provide the $\mathrm{B}$ class organ identity function. Development 122, 11-22.

LEE, H., SUH, S.S., PARK, E., CHO, E., AHN, J.H., KIM, S.G., LEE, J.S., KWON, Y.M., and LEE, I. (2000). The AGAMOUS-LIKE 20 MADS domain protein integrates floral inductive pathways in Arabidopsis. Genes Dev 14, 2366-2376.

LILJEGREN, S.J., GUSTAFSON-BROWN, C., PINYOPICH, A., DITTA, G.S., and YANOFSKY, M.F. (1999). Interactions among APETALA1, $\angle E A F Y$, and TERMINAL FLOWER1 specify meristem fate. Plant Cell 11, 1007-1018.

LOHMANN, J.U., and WEIGEL, D. (2002). Building beauty: the genetic control of floral patterning. Dev Cell 2, 135-142.

LOHMANN, J.U., HONG, R.L., HOBE, M., BUSCH, M.A., PARCY, F., SIMON, R., and WEIGEL, D. (2001). A molecular link between stem cell regulation and floral patterning in Arabidopsis. Cell 105, 793-803.

LONG, J., and BARTON, M.K. (2000). Initiation of axillary and floral meristems in Arabidopsis. Dev Biol 218, 341-353.

MANDEL, M.A., GUSTAFSON-BROWN, C., SAVIDGE, B., and YANOFSKY, M.F. (1992). Molecular characterization of the Arabidopsis floral homeotic gene APETALA1. Nature 360, 273-277.

MARTINEZ-ZAPATER, J.M., COUPLAND, G., DEAN, C., and KOORNNEEF, M. (1994). The transition to flowering in Arabidopsis. In Arabidopsis, E.M. Meyerowitz and C.R. Somerville, eds (New-York: Cold Spring Harbor Laboratory Press), pp. 403-434.

MICHAELS, S.D., and AMASINO, R.M. (1999). FLOWERING LOCUS C encodes a novel MADS domain protein that acts as a repressor of flowering. Plant Cell $11,949-956$

MICHAELS, S.D., HE, Y., SCORTECCI, K.C., and AMASINO, R.M. (2003a). Attenuation of FLOWERINGLOCUSCactivity as a mechanism for the evolution of summer-annual flowering behavior in Arabidopsis. Proc Natl Acad Sci U S A 100, 10102-10107.

MICHAELS, S.D., HIMELBLAU, E., KIM, S.Y., SCHOMBURG, F.M., and AMASINO, R.M. (2005). Integration of flowering signals in winter-annual Arabidopsis. Plant Physiol 137, 149-156.

MICHAELS, S.D., DITTA, G., GUSTAFSON-BROWN, C., PELAZ, S., YANOFSKY, M., and AMASINO, R.M. (2003b). AGL24 acts as a promoter of flowering in Arabidopsis and is positively regulated by vernalization. Plant J 33, 867-874.

MOON, J., LEE, H., KIM, M., and LEE, I. (2005). Analysis of flowering pathway integrators in Arabidopsis. Plant Cell Physiol.

MOON, J., SUH, S.S., LEE, H., CHOI, K.R., HONG, C.B., PAEK, N.C., KIM, S.G., and LEE, I. (2003). The SOC1 MADS-box gene integrates vernalization and gibberellin signals for flowering in Arabidopsis. Plant J 35, 613-623.

MOURADOV, A., CREMER, F., and COUPLAND, G. (2002). Control of flowering time: interacting pathways as a basis for diversity. Plant Cell 14, S111-130.

NILSSON, O., LEE, I., BLAZQUEZ, M.A., and WEIGEL, D. (1998). Flowering-time genes modulate the response to $\angle E A F Y$ activity. Genetics 150, 403-410.

NOH, Y.S., and AMASINO, R.M. (2003). PIE1, an ISWI family gene, is required for FLC activation and floral repression in Arabidopsis. Plant Cell 15, 1671-1682.

NOH, Y.S., BIZZELL, C.M., NOH, B., SCHOMBURG, F.M., and AMASINO, R.M. (2004). EARL Y FLOWERING 5 acts as a floral repressor in Arabidopsis. Plant $\mathrm{J} 38,664-672$.

ONOUCHI, H., IGENO, M.I., PERILLEUX, C., GRAVES, K., and COUPLAND, G. (2000). Mutagenesis of plants overexpressing CONSTANS demonstrates novel interactions among Arabidopsis flowering-time genes. Plant Cell 12, 885-900.

PARCY, F., BOMBLIES, K., and WEIGEL, D. (2002). Interaction of $\angle E A F Y$, AGAMOUS and TERMINAL FLOWER1 in maintaining floral meristem identity in Arabidopsis. Development 129, 2519-2527.
PARCY, F., NILSSON, O., BUSH, M.A., LEE, I., and WEIGEL, D. (1998). A genetic framework for floral patterning. Nature 395, 561-566.

PINEIRO, M., GOMEZ-MENA, C., SCHAFFER, R., MARTINEZ-ZAPATER, J.M., and COUPLAND, G. (2003). EARLY BOLTING IN SHORT DAYS is related to chromatin remodeling factors and regulates flowering in Arabidopsisby repressing FT. Plant Cell 15, 1552-1562.

PUTTERILL, J., ROBSON, F., LEE, K., SIMON, R., and COUPLAND, G. (1995). The CONSTANS gene of Arabidopsis promotes flowering and encodes a protein showing similarities to zinc finger transcription factors. Cell 80, 847-857.

RATCLIFFE, O.J., BRADLEY, D.J., and COEN, E.S. (1999). Separation of shoot and floral identity in Arabidopsis. Development 126, 1109-1120.

RATCLIFFE, O.J., KUMIMOTO, R.W., WONG, B.J., and RIECHMANN, J.L. (2003). Analysis of the Arabidopsis MADS AFFECTING FLOWERING gene family: MAF2prevents vernalization by short periods of cold. Plant Cell 15, 1159-1169.

RATCLIFFE, O.J., AMAYA, I., VINCENT, C.A., ROTHSTEIN, S., CARPENTER, R., COEN, E.S., and BRADLEY, D.J. (1998). A common mechanism controls the life cycle and architecture of plants. Development 125, 1609-1615.

Ruiz-Garcia, L., Madueno, F., Wilkinson, M., Haughn, G., Salinas, J., and MartinezZapater, J.M. (1997). Different roles of flowering-time genes in the activation of floral initiation genes in Arabidopsis. Plant Cell 9, 1921-1934.

SAMACH, A., ONOUCHI, H., GOLD, S.E., DITTA, G.S., SCHWARZ-SOMMER, Z., YANOFSKY, M.F., and COUPLAND, G. (2000). Distinct roles of CONSTANS target genes in reproductive development of Arabidopsis. Science 288, 16131616.

SCHMID, M., UHLENHAUT, N.H., GODARD, F., DEMAR, M., BRESSAN, R., WEIGEL, D., and LOHMANN, J.U. (2003). Dissection of floral induction pathways using global expression analysis. Development 130, 6001-6012.

SCORTECCI, K., MICHAELS, S.D., and AMASINO, R.M. (2003). Genetic interactions between FLMand other flowering-time genes in Arabidopsis thaliana. Plant Mol Biol 52, 915-922.

SCORTECCI, K.C., MICHAELS, S.D., and AMASINO, R.M. (2001). Identification of a MADS-box gene, FLOWERING LOCUS M, that represses flowering. Plant $J$ 26, 229-236.

SESSIONS, A., YANOFSKY, M.F., and WEIGEL, D. (2000). Cell-cell signaling and movement by the floral transcription factors LEAFY and APETALA1. Science 289, 779-782.

SIMON, R., IGEÑO, M.I., and COUPLAND, G. (1997). Activation of floral meristem identity genes in Arabidopsis. Nature 382, 59-62.

SIMPSON, G.G., and DEAN, C. (2002). Arabidopsis, the Rosetta stone of flowering time? Science 296, 285-289.

SIMPSON, G.G., GENDALL, A.R., and DEAN, C. (1999). When to switch to flowering. Annu Rev Cell Dev Biol 15, 519-550.

SMYTH, D.R., BOWMAN, J.L., and MEYEROWITZ, E.M. (1990). Early flower development in Arabidopsis. Plant Cell 2, 755-767.

SUAREZ-LOPEZ, P., WHEATLEY, K., ROBSON, F., ONOUCHI, H., VALVERDE, F., and COUPLAND, G. (2001). CONSTANS mediates between the circadian clock and the control of flowering in Arabidopsis. Nature 410, 1116-1120.

SUH, S.S., CHOI, K.R., and LEE, I. (2003). Revisiting phase transition during flowering in Arabidopsis. Plant Cell Physiol 44, 836-843.

SUNG, S., and AMASINO, R.M. (2004a). Vernalization and epigenetics: how plants remember winter. Curr Opin Plant Biol 7, 4-10.

SUNG, S., and AMASINO, R.M. (2004b). Vernalization in Arabidopsis thaliana is mediated by the PHD finger protein VIN3. Nature 427, 159-164.

TAKADA, S., and GOTO, K. (2003). TERMINAL FLOWER2, an Arabidopsis homolog of HETEROCHROMATIN PROTEIN1, counteracts the activation of FLOWERING LOCUS T by CONSTANS in the vascular tissues of leaves to regulate flowering time. Plant Cell 15, 2856-2865.

VALVERDE, F., MOURADOV, A., SOPPE, W., RAVENSCROFT, D., SAMACH, A., and COUPLAND, G. (2004). Photoreceptor regulation of CONSTANS protein in photoperiodic flowering. Science 303, 1003-1006.

WAGNER, D., and MEYEROWITZ, E.M. (2002). SPLAYED, a novel SWI/SNF ATPase homolog, controls reproductive development in Arabidopsis. Curr Biol 12, 85-94. 
WAGNER, D., SABLOWSKI, R.W., and MEYEROWITZ, E.M. (1999). Transcriptional activation of $A P E T A L A 1$ by $\angle E A F Y$. Science 285, 582-584.

WAGNER, D., WELLMER, F., DILKS, K., WILLIAM, D., SMITH, M.R., KUMAR, P.P., RIECHMANN, J.L., GREENLAND, A.J., and MEYEROWITZ, E.M. (2004). Floral induction in tissue culture: a system for the analysis of $\angle E A F Y$-dependent gene regulation. Plant $\mathrm{J} 39,273-282$.

WEIGEL, D., and MEYEROWITZ, E.M. (1993). LEAFY controls meristem identity in Arabidopsis. In Cellular Communications in Plants, R. Amasino, ed (New York: Plenum Press), pp. 115-122.

WEIGEL, D., and MEYEROWITZ, E.M. (1994). Morphology and development of leafy mutants. In Arabidopsis: An Atlas of Morphology and Development, J.L. Bowman, ed (New York: Springer), pp. 206-211.

WEIGEL, D., and NILSSON, O. (1995). A developmental switch sufficient for flower initiation in diverse plants. Nature 377, 495-500.

WEIGEL, D., ALVAREZ, J., SMYTH, D.R., YANOFSKY, M.F., and MEYEROWITZ, E.M. (1992). $\angle E A F Y$ controls floral meristem identity in Arabidopsis. Cell 69, 843-859.
WILLIAM, D.A., SU, Y., SMITH, M.R., LU, M., BALDWIN, D.A., and WAGNER, D. (2004). Genomic identification of direct target genes of LEAFY. Proc Natl Acad Sci U S A 101, 1775-1780.

WILSON, R.N., HECKMAN, J.W., and SOMERVILLE, C.R. (1992). Gibberellin is required for flowering in Arabidopsis thaliana under short days. Plant Physiol. 100, 403-408.

WU, X., DINNENY, J.R., CRAWFORD, K.M., RHEE, Y., CITOVSKY, V., ZAMBRYSKI, P.C., and WEIGEL, D. (2003). Modes of intercellular transcription factor movement in the Arabidopsis apex. Development 130, 3735-3745.

YU, H., XU, Y., TAN, E.L., and KUMAR, P.P. (2002). AGAMOUS-LIKE 24, a dosage-dependent mediator of the flowering signals. Proc Natl Acad Sci U S A 99, 16336-16341.

YU, H., ITO, T., WELLMER, F., and MEYEROWITZ, E.M. (2004). Repression of AGAMOUS-LIKE 24 is a crucial step in promoting flower development. Nat Genet 36, 157-161.

ZEEVAART, J.A.D. (1976). Physiology of flower formation. Ann. Rev. Plant. Physiol. 27, 321-348. 